\begin{tabular}{c} 
Tersedia online di: http://ejournal-balitbang.kkp.go.id/index.php/bawal \\
e-mail:bawal.puslitbangkan@ gmail.com \\
BAWAL WIDYA RISET PERIKANAN TANGKAP \\
Volume 8 Nomor 2 Agustus 2016 \\
p-ISSN: 1907-8226 \\
e-ISSN: 2502-6410 \\
BAWAL \\
Nomor Akreditasi: 620/AU2/P2MI-LIPI/03/2015 \\
\hline \hline
\end{tabular}

\title{
POLA DAN MUSIM PEMIJAHAN IKAN TONGKOL KOMO (Euthynnus affinis Cantor, 1850) DI LAUT JAWA
}

\section{PATTERNS AND SPAWNING SEASON OF KAWAKAWA (Euthynnus affinis Cantor, 1850) IN THE JAVA SEA}

\author{
Thomas Hidayat*, Endah Febrianti dan Yoke Hani Restiangsih \\ ${ }^{1}$ Balai Penelitian Perikanan Laut, Komplek Pelabuhan Perikanan Samudera, Muara Baru - Jakarta Utara, 14430, Indonesia \\ Teregistrasi I tanggal: 23 Januari 2015; Diterima setelah perbaikan tanggal: 08 Agustus 2016; \\ Disetujui terbit tanggal: 11 Agustus 2016
}

\begin{abstract}
ABSTRAK
Ikan tongkol komo (Euthynnus affinis, Cantor 1850) merupakan salah satu jenis kelompok ikan pelagis besar yang banyak didaratkan oleh armada jarring insang dan pukat cincin di Tegal. Tersedianya data dan informasi tentang pola dan musim pemijahan merupakan bagian dari pengetahuan yang diperlukan untuk mengetahui status sumberdaya bagi upaya pengelolaanya. Penelitian ini ditujukan untuk mendapatkan pola dan musim pemijahan ikan tongkol komo di Laut Jawa khususnya di pantai Tegal dan sekitarnya. Penelitian dilakukan pada bulan Februari-Desember 2012 di tempat pendaratan ikan kota Tegal, Jawa Tengah. Pendugaan pola pemijahan berdasarkan pengamatan sebaran frekuensi diameter telur sedangkan pendugaan musim pemijahan menggunakan pendekatan Indeks Kematangan Gonad (IKG) atau Gonado somatic index (GSI) bulanan. Analisis data oseanografi khususnya suhu permukaan laut (SPL) dan konsentrasi klorofil-a berdasarkan citra satelit Aqua Modis digunakan sebagai data dukung musim pemijahan. Hasil penelitian menunjukkan pola pemijahan tongkol komo di Laut Jawa memiliki strategi reproduksi beberapa kali memijah (partial spawner). Fekunditas berkisar antara 225.760-2.601500 telur. Musim pemijahan terjadi pada Juni-Agustus dimana konsentrasi klorofil-a tinggi.
\end{abstract}

Kata Kunci: Tongkol komo; Euthynnus affinis; musim pemijahan; fekunditas; Laut Jawa

\begin{abstract}
Kawakawa (Euthynnus affinis, Cantor 1850) is one of large pelagic species group caught by drift gill nets and purse seine fisheries in the Java Sea. The information of spawning characteristics is crucial for fisheries management. This research aims to determine the spawning strategy of kawakawa in the Java Sea mainly in Tegal and adjacent waters. Observation has been conducted during February-December 2012 in Tegal, Central Java. The estimation the spawning season determined by using Gonad somatic index (GSI) and investigated with profiling oceanographic data on sea surface temperature (SST) and concentration of chlorophyll-a derived from Aqua Modis satellite imagery. The results showed the reproductive strategy of kawakawa in the Java Sea is partial spawner. Fecundity ranged between 225,760-2,601,500 eggs and the spawning season occurs in June-August where concentrations of chlorophyll-a high.
\end{abstract}

Keywords: Kawakawa; Euthynnus affinis; spawning season; fecundity; Java Sea

\section{PENDAHULUAN}

Tongkol komo (Euthynnus affinis) merupakan spesies tuna neritik yang daerah penyebarannya mulai dari Pasifik barat, perairan Jepang, Filipina, Kepulauan Indonesia, Australia, periaran India sampai teluk Persia (Collette \& Nauen,1983).
Produksi ikan tongkol komo di Laut Jawa tahun 2014 sebesar 10.637 ton atau sekitar $5,1 \%$ dari total produksi nasional (Anonimous, 2015), produksi ikan ini, 33\% nya dihasilkan dari alat tangkap jaring insang hanyut dan $67 \%$ nya dari pukat cincin (Suwarso, 2009). 
Penelitian reproduksi ikan tentang aktivitas pemijahan adalah komponen yang sangat penting terkait karaktristik biologis sumberdaya ikan untuk mendukung penyusunan opsi pengelolaan khususnya perlindungan ikan yang sedang dan akan memijah (Mackie \& Lewis, 2001). Penelitian fekunditas tongkol komo banyak dilakukan di Samudera Hindia dan Pasifik barat. Menurut Rao (1964), tongkol komo (Euthynnus affinis) di perairan India memiliki fekunditas antara 790.000-2.500.000 butir telur dengan panjang tubuh (FL) $48-65 \mathrm{~cm}$. Muthiah (1985) menyatakan fekunditas ikan tongkol komo di perairan India 202.000 - 1.570 .000 butir telur dengan panjang tubuh (FL) antara 39,4 - 67,0 cm. Klinmuang (1978) menyatakan fekunditas ikan tongkol komo di Laut Cina Selatan antara 585.000 - 2.593.000 butir telur dengan panjang tubuh (FL)antara 39,5 - 51,0 cm .

Musim pemijahan ikan tongkol komo di perairan India berlangsung pada bulan Maret - Juni dan puncaknya pada bulan April - Mei (Rohit et al., 2012.), di Laut Cina Selatan musim pemijahan pada bulan Juni - Agustus (Williamson, 1970). Penelitian musim pemijahan tongkol komo di Laut Jawa masih sangat terbatas.

Tujuan dari penelitian ini untuk mengetahui pola dan musim pemijahan khususnya fekunditas, diameter telur, sebaran IKG (indeks kematangan gonad), serta tingkat keeratan hubungan dengan perubahan SPL (suhu permukaan laut) dan Klorofil-a.

\section{BAHANDANMETODE}

Penelitian dilakukan pada bulan Februari-Desember 2012. Lokasi pengambilan sampel di tempat pelelangan ikan (TPI) Pelabuhan Perikanan Pantai Tegal. Pengamatan tingkat kematangan gonad (TKG) dan IKG dilakukan terhadap 204 sampel ikan tongkol komo. Estimasi fekunditas dilakukan dengan mengambil spescimen telur yang yang dikategorikan matang gonad (TKG III dan IV). Cara mendapatkan telur dengan pembedahan perut ikan, gonad (telur) diambil dari perut ikan dengan alat pinset, telur utuh ini ditimbang dan dicatat, kemudian telur tersebut diambil sebagian (selanjutnya disebut sampel telur) ditimbang kemudian dicatat. Sampel telur diawetkan dengan larutan gilson, disimpan dalam plastik (wadah) dan di analisis ke laboratorium biologi Balai Penelitian Perikanan Laut, Muara Baru untuk dianalisis.

Alat dan pelengkapan yang digunakan untuk membantu penelitian yaitu timbangan digital untuk menimbang bobot telur, spatula, kertas saring, gelas ukur, pipet $1 \mathrm{ml}$, objek gelas, cover glass, mikroskop, handtally counter, tisu dan alat tulis.

\section{Analisis Data}

Fekunditas diamati dengan menggunakan metode gravimetrik, memiliki persamaan sebagai berikut (Effendie, 1997):

$F=\left(\frac{G}{Q}\right) X N$

Keterangan:

$\mathrm{F}$ = fekunditas (butir)

$\mathrm{G}=$ berat gonad (gram)

$\mathrm{N}=$ jumlah telur tiap gonad contoh (butir)

$\mathrm{Q}=$ berat $\operatorname{gonad}$ contoh $(\mathrm{gram})$

Hubungan fekunditas dengan panjang dianalisis dengan rumus Holden \& Raitt (1974):

$\mathrm{F}=\mathrm{a} \mathrm{L}^{\mathrm{b}}$

dimana:

$\mathrm{F} \quad=$ fekunditas (butir)

$\mathrm{L} \quad=$ panjang total ikan $(\mathrm{mm})$

$\mathrm{W} \quad=$ bobot tubuh ikan (gram)

$\mathrm{a}$ dan $\mathrm{b}=$ konstanta hasil regresi

Diameter telur dianalisis dengan cara mengelompokkan ukuran diameter telur kemudian digambarkan dalam grafik polygon, dengan melihat penyebaran modusnya, sehingga dapat lihat pola pemijahannya (Murua \& Rey. 2003). Pengukuran telur ini dilakukan pada telur-telur ikan dewasa dengan kematangan gonad (TKG) III \& IV.

Penentuan tingkat kematangan gonad dilakukan dengan acuan Holden \& Raitt (1974) yang terdiri atas lima stadium (Tabel 1). 
Tabel 1. Tingkat kematangan gonad ikan Table 1. Gonad maturity stage of fish

\begin{tabular}{cl}
\hline $\begin{array}{l}\text { Tingkat Kematangan gonad } \\
\text { (Gonad maturity stage) }\end{array}$ & Keterangan/ Remarks \\
\hline I & Ovarium dan testes, panj ang $1 / 3$ rongga perut. Ovarium transparan dan \\
(Belum matang) & kemerah-merahan. Telur tidakn dapat dilihat dengan mata biasa \\
II & Panjang ovarium dan testes sekitar $1 / 2$ rongga perut. Ovarium transparan \\
(Belum matang) & dan kemerah-merahan. Telur belum bisa dilihat dengan mata biasa. \\
III & Panjang ovarium dan testes sekitar $2 / 3$ rongga perut. Ovariurium \\
(matang) & kuning kemerah-merahan dan butiran telur sudah nampak \\
IV & Panjang ovarium $2 / 3$ dari rongga perut. Ovarium berwarna orange dengan \\
(matang) & pembuluh darah kurang jelas. Butiran telur terlihat jelas \\
V & Ovarium mengerut sampai $1 / 2$ dari rongga perut sebagai tanda sudah \\
(spent) & terjadi pemijahan, tetapi masih ada butir-butir telur. \\
\hline
\end{tabular}

Sumber/source: Holden \& Raitt (1974)

Indeks Kematangan Gonad (IKG) atau Gonado Somatic Index (GSI) adalah nilai persentase perbandingan berat gonad dan berat ikan, nilai indeks ini semakin lama semakin besar sampai batas kisaran maksimum, kemudian akan terjadi penurunan. Dengan mengetahui IKG ini kita bisa memperkirakan musim memijah ikan. Indeks IKG atau GSI menurut dianalisis dengan rumus Effendie (2002):

$\mathrm{IKG}=(\mathrm{Bg} / \mathrm{Bt}) \times 100 \%$

dimana:

IKG : indeks Kematangan Gonad

$\mathrm{Bg}$ : berat gonad (gram)

$\mathrm{Bt}$ : berat tubuh ikan - berat gonad (gram)

Analisis data Suhu permukaan laut (SPL) dan klorofila diambil dari citra satelit Aqua MODIS daytime level 3 SMI (Standar Mapped Image) bulanan dengan tahun perekaman 2012, resolusi pixel $4.6 \mathrm{~km}$ dari: oceancolor.gsfc.nasa.gov.

\section{HASIL DAN BAHASAN \\ Hasil}

\section{Fekunditas dan Diameter Telur}

Fekunditas ikan tongkol komo (Euthynnus affinis) di Laut Jawa pada ikan dengan panjang tubuh (FL) antara 38 - $52 \mathrm{~cm}$ terdapat telur antara $225.760-2.601 .500$ butir. Kisaran diameter telur ikan tongkol komo dewasa yaitu antara 0,11-0,65 mm (Gambar 1). Diameter yang paling banyak terdapat pada ukuran $0,44 \mathrm{~mm}$

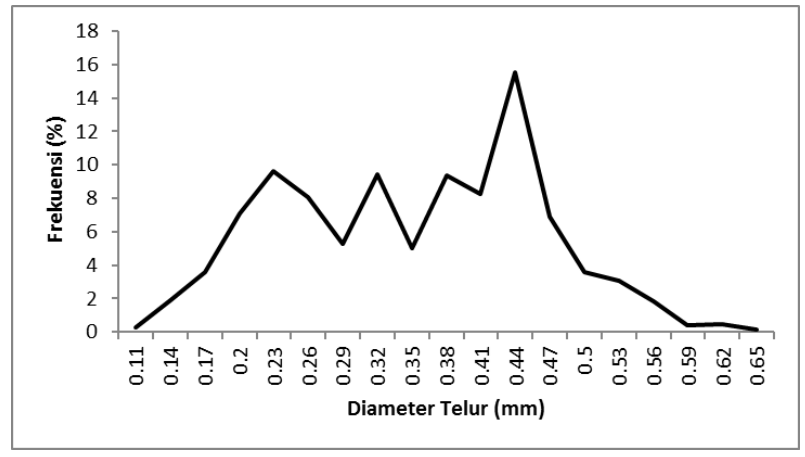

Gambar 1. Sebaran diameter telur ikan tongkol komo. Figure 1. Eggs diameter distribution of kawakawa.

Analisis hubungan antara fekunditas dengan panjang ikan pada TKG IV diperoleh persamaan $\mathrm{F}=0.0509 \mathrm{~L}^{4.414}$, $\mathrm{R}^{2}=0.364$ (Gambar 2.).

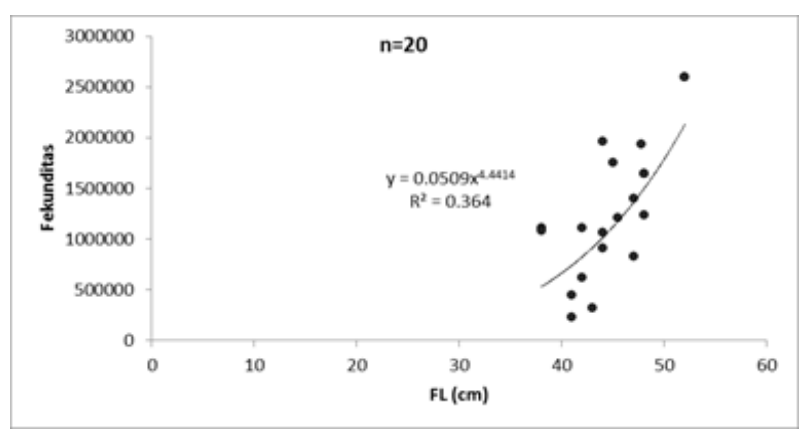

Gambar2. Hubungan fekunditas dengan panjang ikan tongkol komo.

Figure 2. Relationship of length and fecundity of kawakawa. 


\section{Tahap Reproduksi}

Dengan membandingkan Indeks kematangan gonad (IKG) dengan tingkat kematangan gonad (TKG) akan diketahui hubungan antara perkembangan didalam dan diluar gonad, atau nilai-nilai morfologi yang dikuantitatifkan.

Hubungan antara IKG dengan TKG ikan tongkol komo jantan dan betina menunjukkan pola yang sama, yaitu memiliki indeks IKG terus meningkat mulai dari TKG I sampai puncaknya pada TKG IV diikuti dengan penurunan pada TKG V. Hal ini karena pada TKG V ikan sudah memijah (spent) sehingga IKG menurun. (Gambar 3. dan 4.)

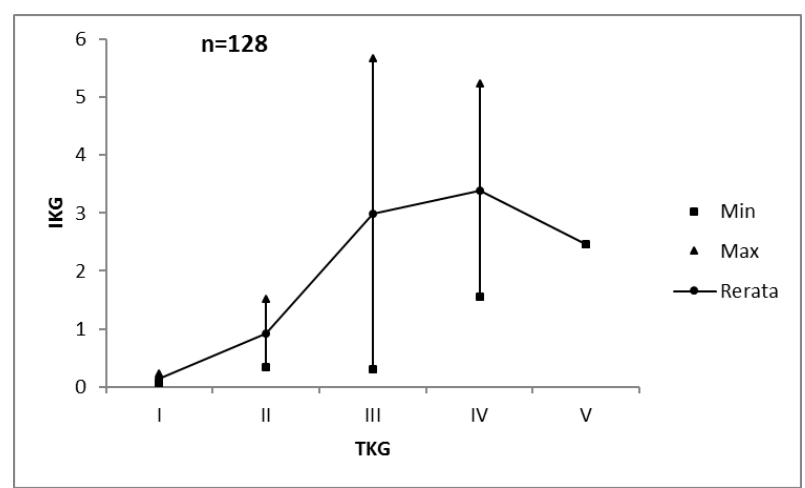

Gambar 3. Perkembangan IKG terhadap TKG ikan tongkol komo jantan.

Figure 3. Development GSI to gonadal maturity stage of male kawakawa.

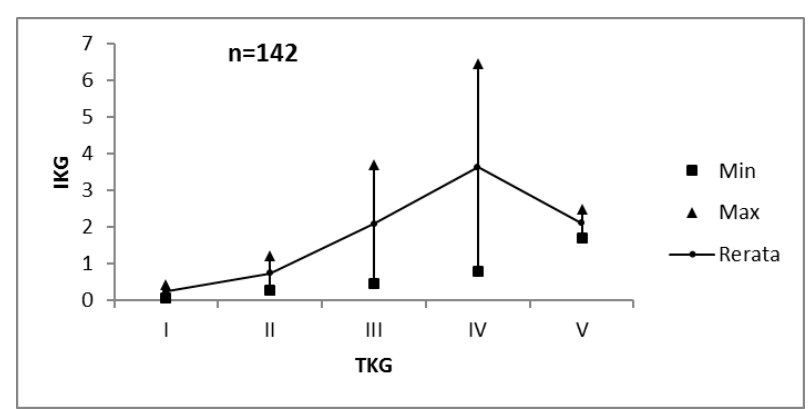

Gambar4. Perkembangan IKG terhadap TKG ikan tongkol komo betina.

Figure 4. Development GSI to gonadal maturity stage of female kawakawa.

\section{Musim Pemijahan}

Perkembangan IKG bulanan ikan tongkol komo jantan (Gambar 5) menunjukkan bahwa nilai tertinggi terjadi pada bulan Maret dan Mei, ikan memijah biasanya sebulan kemudian setelah puncak IKG (Widodo, 1988; Claereboudt et al., 2005). Sehingga ikan memijah pada bulan April dan Juni.

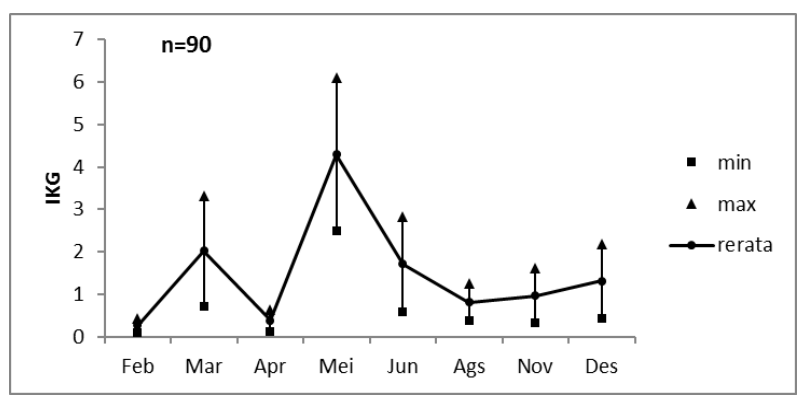

Gambar 5. Perkembangan IKG bulanan ikan tongkol komo jantan.

Figure 5. Monthly GSI development of male kawakawa.

Perkembangan IKG bulanan ikan tongkol komo betina (Gambar 6.) menunjukkan bahwa indeks tertinggi terjadi pada bulan Maret dan Juni sehingga ikan memijah bulan April dan Juni.

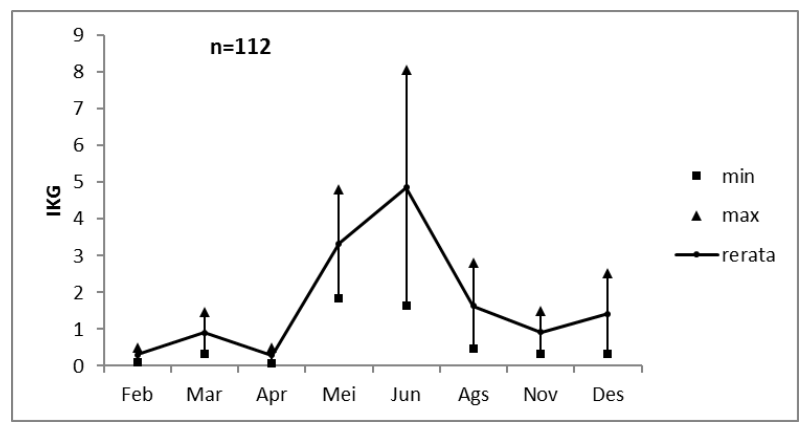

Gambar 6. Perkembangan IKG bulanan ikan tongkol komo betina.

Figure 6. Monthly GSI development of female kawakawa

Dari perkembangan IKG ikan tongkol komo jantan dan betina terlihat bahwa puncak musim pemijahan pada JuniJuli Agustus. Pemijahan pada bulan April terjadi namun dalam jumlah yang relatif rendah (minor)

\section{Suhu Permukaan Laut (SPL) dan Konsentrasi Klorofil-a}

Profil rata-rata suhu permukaan laut (SPL) di Laut Jawa memperlihatkan bahwa suhu tertinggi terjadi pada bulan April dan kemudian mulai menurun pada bulan Mei (Gambar 8.) dan SPL kembali meningkat bulan November dan mulai menurun pada bulan Desember, hal ini berbanding terbalik dengan konsentrasi rata-rata klorofila yang menunjukkan pada bulan Juni dan Januari tertinggi (Gambar 9.). 


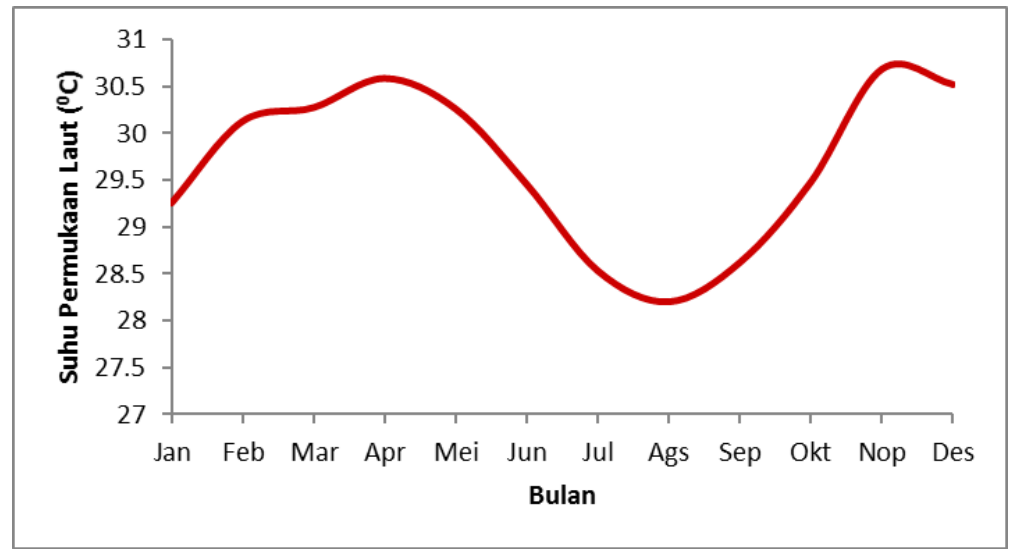

Gambar 8. Suhu permukaan laut (SPL) bulanan di Laut Jawa, tahun 2012.

Figure 8. Monthly sea surface temperature (SST) of the Java Sea, 2012. (Sumber/Source: Aqua Modis Satellite)

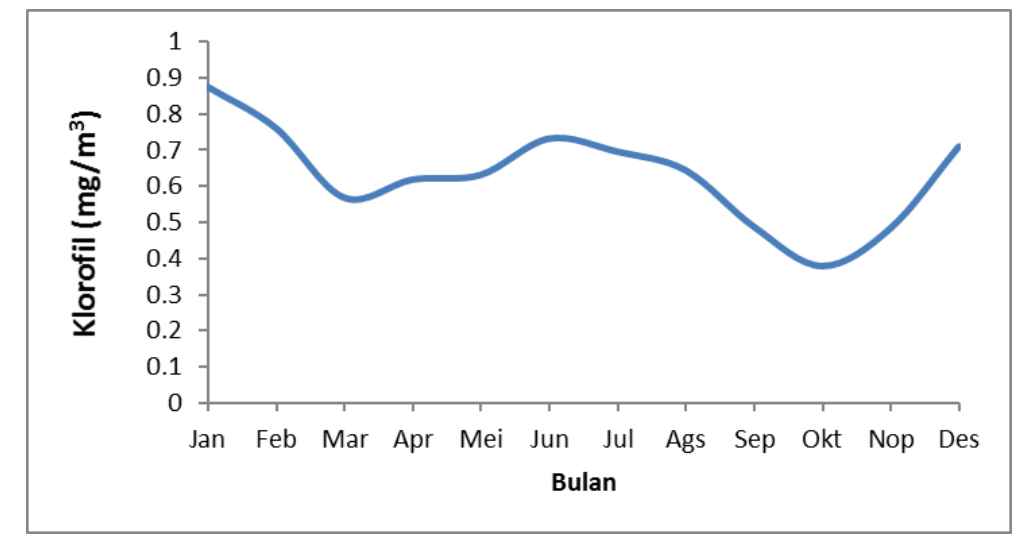

Gambar 9. Kadar klorofil-a bulanan di Laut Jawa, tahun 2012.

Figure 9. Monthly chlorophyll a concentration of the Java Sea 2012.

(Sumber/Source: Aqua Modis Satellite)

\section{Bahasan}

Fekunditas ikan tongkol komo (Euthynnus affinis) di Laut Jawa berkisar antara 225.760 - 2.601.500 butir telur dengan panjang tubuh (FL) berkisar antara $38-52 \mathrm{~cm}$. Menurut Rao (1964), ikan Euthynnus affinis di perairan India memiliki fekunditas antara 790.000-2.500.000 butir telur dengan panjang tubuh (FL)antara $48-65 \mathrm{~cm}$. Muthiah (1985) menyatakan fekunditas ikan tongkol komo di perairan India $202.000-1.570 .000$ telur dengan panjang tubuh (FL) antara 39,4 - 67,0 cm. Klinmuang (1978) menyatakan fekunditas ikan tongkol komo di Laut Cina Selatan 585.000 - 2.593.000 butir telur dengan panjang tubuh (FL)antara 39,5 - 51,0 cm. Perbedaan jumlah telur ikan tongkol ini dimungkinkan karena perbedaan kondisi perairan dan makanan sebagaimana diungkapkan Effendie (2002) bahwa fekunditas dipengaruhi oleh makanan dan kondisi lingkungan perairan.
Hubungan antara fekunditas dengan panjang ikan tongkol komo memperlihatkan koefisien korelasi $\left(\mathrm{R}^{2}\right)$ yang rendah atau tidak berbanding lurus. Nilai $R^{2}$ yang rendah menunjukkan bervariasinya fekunditas pada ukuran panjang yang sama (Effendi. 1979).

Diameter telur ikan tongkol komo dewasa di Laut Jawa berbeda dengan penelitian Nissar et al., (2015) di peraiaran Veraval India yaitu pada kisaran: 0,34 - 0,61 mm, namun ukuran diameter maksimal hampir sama. Perbedaan ini diduga karena adanya perbedaan kondisi habitat.

Distribusi diameter telur tongkol komo beragam mulai telur yang berdiameter kecil hingga telur berdiameter besar, dimana terdapat dua modus (heterogen). Adanya modus yang heterogen menunjukkan tongkol komo memijah tidak sekaligus (partial spawner). Hal ini sesuai dengan pernyataan Yustina (2002) yang menyatakan bahwa sebaran diameter telur yang heterogen mengindikasikan 
ikan bersifat partial spawner. Hal ini disebabkan proses pematangan di dalam ovari ikan tongkol komo berlangsung tidak serentak. Selanjutnya Effendie (2002) menjelaskan bahwa perkembangan telur dipengaruhi oleh nutrisi (makanan) dan kondisi lingkungan.

Berdasarkan perkembangan IKG tongkol komo jantan dan betina puncak musim pemijahan di Laut Jawa terjadi pada bulan Juni, Juli dan Agustus. Hal ini hampir sama dengan ikan layang (Decapterus spp) di Laut Jawa yang memijah pada bulan Juni dan Desember (Widodo, 1988). Musim memijah ikan tongkol komo di Laut Jawa hampir sama dengan musim memijah di perairan Thailand yaitu dari bulan April-Juli dan Desember-Januari. (Cheunpan, 1984). Perbedaan musim memijah ini karena kondisi perairan/habitat ikan ini berbeda-beda, seperti suhu permukaan, dan kelimpahan nutrisi (Smith, 2001)

Pada bulan Juni-Agustus suhu permukaan Laut Jawa rendah yaitu sekitar $28^{\circ} \mathrm{C}-29,5^{\circ} \mathrm{C}$ dan konsentrasi Klorofil a tinggi 0,73-0,64 mg/m (Gambar 8 dan 9) hal ini karena pada musim timur arus permukaan bergerak dari Laut Banda melalui Laut Flores dan dari Selat Makassar ke Laut Jawa dimana banyak terjadi upwelling di perairan itu, sehingga di Laut Jawa kadar klorofil-a tinggi dan SPL nya rendah (Hendiarti et al., 2005).

Musim pemijahan terjadi pada musim timur (JuniAgustus) di Laut Jawa pada saat SPL rendah dan kadar klorofil-a tinggi., Hal ini karena sering terjadi upwelling di bagian selatan Selat Makassar (Illahude, 1970; Inaku, 2011), dan di Laut Banda (Sediadi, 2004 ). Pada musim timur arus permukaan bergerak dari Laut Banda melalui Laut Flores dan dari Selat Makassar ke Laut Jawa membawa air yang dingin dan kaya akan nutrisi sehingga di Laut Jawa kadar klorofil-a tinggi dan SPL nya rendah (Hendiarti et al., 2005). Hal ini sesuai dengan pendapat Claereboudt et al. (2002) dan Smith (2001), bahwa mesim pemijahan ikan dipengaruhi oleh, suhu air laut, kelimpahan nutrisi dan arus permukaan laut.

Musim pemijahan di Laut Jawa terjadi pada bulan Juni, Juli dan Agustus (musim timur) kadar klorofil-a tinggi. Klorofil-a yang tinggi menunjukkan melimpahnya fitoplankton dan selanjutnya akan diikuti zooplankton. Karena zooplankton merupakan makanan dari larva ikan tongkol komo yang baru menetas (Siraimeetan, 1985). Berdasarkan match/mismatch hypothesis, ikan memijah biasanya saat kondisi perairan planktonnya melimpah yang merupakan makanannya, hal ini untuk kelangsungan hidup larva ikan dan rekrutmen. (Cushing (1975) dan Durant et al. (2007).

\section{KESIMPULAN}

Fekunditas ikan tongkol komo berkisar antara 225.760 -2.601 .500 butir telur, diameter telur berkisar antara $0,11-$ $0,65 \mathrm{~mm}$, dengan pola pemijahan beberapa kali dalam satu musim pemijahan (partial spawner). Puncak musim memijah ikan tongkol komo di Laut Jawa pada bulan Juni sampai Agustus bersamaan dengan musim timur pada saat suhu permukaan laut rendah (antara $28,0-29,5^{\circ} \mathrm{C}$ ) dan kadar klorofil-a tinggi (antara 0,73-0,64 mg/m $\mathrm{m}^{3}$ ).

\section{PERSANTUNAN}

Tulisan ini merupakan kegiatan Penelitian Distribusi dan Kelimpahan Sumberdaya Ikan Pelagis Besar di WPP716 Laut Sulawesi dan WPP-712 Laut Jawa. Penulis mengucapkan terima kasih kepada Ir. Duto Nugroho, Dr. Khairul Amri, dan semua tim peneliti atas komentar dan saran yang sangat berharga untuk penerbitan tulisan ini.

\section{DAFTAR PUSTAKA}

Anonimous. (2015). Statistik Perikanan Tangkap di Laut Menurut Wilayah Pengelolaan Perikanan Laut Negara Republik Indonesia (WPP-NRI) 2005-2014. Kementerian Kelautan Perikanan Tangkap, Direktorat Jenderal Perikannan Tangkap, 2015.

Cheunpan, A. (1984). Sexual maturity, size at first maturity and spawning season of longtail tuna (Thunnus. tonggol), eastern little tuna (Euthynnus affinis) and frigate mackerel (Auxis thazard) in the Gulf of Thailand. Rep.Mar.Fish.Div.Dep.Fish. Bangkok, 43:22 p.

Claereboudt, M.R., Al-Oufi, H., Hermosa, G., \& Jamir, T.V. (2002). Plausible cause of massive fish kills on the AlBatinah coast, Sultanate of Oman. Sultan Qaboos. In: Claereboudt, M.R., H.S. Al-Oufi, J. Mc Ilwain, S. Goddard, (Eds.), International conference on fisheries, aquaculture and environment in the NW Indian Ocean. Sultan Qaboos University, Muscat, p. 123-132.

Claereboudt M.R., McIlwain, J.L., Al-Oufi, H.S., \& AmbuAli, A.A. (2005) Patterns of reproduction and spawning of the kingfish (Scomberomorus commerson, Lac'ep 'ede) in the coastal waters of the Sultanate of Oman. Fisheries Research. 73(3): 273-282.

Collete B.B., \& Nauen, C.E. (1983). FAO Special Catalogue. Vol. 2 Scombrids of the World an Annotated and Illustrated Catalogue of Tunas, Mackerels, Bonitos, and Related Species Known to Date. FAO Fisheries Synopsis. 125(2): 33-34. 
Cushing, D.H. (1975). Marine Ecology and Fisheries. Cambridge University Press. London. 278 p.

Durant, J. M., D O Hjermann, Ottersen, G., \& Stenseth, N. C. (2007). Climate and the match or mismatch between predator requirements and resource availability. Clim Res 33:271-283

Effendie, M. I. (1997). Metoda Biologi Perikanan . Yayasan Agromedia. Yogyakarta, 112 halm.

Effendie, M. I. (2002). Biologi Perikanan. Yayasan Pustaka Nusantara. Bogor, 163 halm.

Hendiarti, N., Suwarso, Aldrin, E., Amri, K., Sachoemar, S. I., $\&$ Wahyono, I. B. (2005). Seasonal variation of pelagic fish catch around Java Sea. Oceanography 18 (4), 112123.

Holden, M.J., \& Raitt, D.F.S. (1974). Manual of Fisheries Science Part 2. Methods of Recources Investigation and their Application. Food and Agriculture Organization. Rome, $135 \mathrm{p}$.

Inaku, D. F. (2011). Analisis Pola Sebaran dan Pengembangan Area Upwelling di Bagian Selatan Selat Makassar. Skripsi. Institut Pertanian Bogor. Bogor.

Illahude A. G. (1970). On the occurance of upwelling in southern Makassar Strait. Marine Research Indonesia. 10,81-107.

Klinmuang, H. (1978). Preliminary Studies on the Biology of Tunas in the West of the Gulf of Thailand and off the East Coast of Peninsular Malaysia. Pelagic Fish.Rep.Mar. Fish.Div.Dep.Fish. Bangkok, 5-27.

Mackie, M., \& Lewis, P.A.W. (2001). Assessment of gonad staging systems and other methods used in the study of the reproductive biology of narrow-barred Spanish mackerel, Scomberomorus commerson, in Western Australia. Fisheries Research Report 136, Department of Fisheries, Government of Western Australia, North Beach.

Murua, H., \& Rey, F.S. (2003). Female reproductive strategies of marine fish spesies of the north Atlantic. J. Northw. Atl. Sci, 33:23-31.
Muthiah, C. (1985). Maturation and Spawning of Euthynnus affinis, Auxis thazard and A. rochei in the Mangalore Inshore Area During 1979 to 1982. In Silas E. G. Ed. Tuna Fisheries of the Exclusive Economic Zone of India: Biology and Stock Assessment. Bull.Cent.Mar.Fish.Res.Inst., Cochin, 36, 71-85.

Nissar, K.K.S., Rashid, F., Girija, G. Phadke \& Desai, A.Y. (2015). Reproductive biology of little tuna (Euthynnus affinis) in the Arabian Sea. Eco. Env. \& Cons. 21 (4): 2015, 115-118.

Nikolsky, G. V. (1963). The Ecology of Fishes. Academic Press. London.

Rao, K.V.N. (1964). An account of the ripe ovaries of some Indian tunas. Proc. Symp. Scombroid Fishes, Part 2. Mar.Biol.Assoc. India. 1, 733-43.

Rohit P., Chellappan, A., Abdusssamad, E. M., Joshi, K. K., Said Koya, K. P., Sivadas, M., Ghosh, S., Rathinam, A. M. M., Kemparaju, S., Dhokia, H. K., Prakasan, D., \& Beni, N. (2012). Fishery and Bionomics of the Little Tuna, Euthynnus Affinis (Cantor, 1849) Exploited From Indian Waters. Indian J. Fish., 59(3), 33-42.

Sediadi A. (2004). Effek upwelling terhadap kelimpahan dan distribusi fitoplankton di perairan Laut Banda dan sekitarnya. Makara, Sains. 8 (2), 43-51.

Siraimeetan, P. (1985). On the occurrence, size distribution, morphometry and feeding habits of the juveniles of Euthynnus affinis (Cantor), Auxis thazard (Lacepede), and Sarda orientalis (Temminck and Schlegel), along the Tuticorin Coast, Gulf of Mannar. Bull. Cent. Mar. Fish. Res. Inst. 36, 104-114.

Smith, S.L. (2001). Understanding the Arabian Sea: reflections on the 1994-1996 Arabian Sea Expedition, Deep Sea Res. II 48 (6-7), 1385-1402.

Suwarso. (2009). Variasi Musiman Hasil tangkapan tongkol (Euthynnus sp.; Fam. Scombridae) di Laut Jawa. Prosiding Seminar Nasional Tahunan VI Hasil Penelitian Perikanan dan Kelautan. Universitas Gajah Mada. Yogyakarta. 6 halm.

Widodo, J. (1988). Population Dynamic and Management of "Ikan Layang", Scad Mackerel, Decapterus spp (Piscess: Carangidae) In Java Sea. Dissertation Doctor of Philosophy. University of Washington,150 p. 
Hidayat, T., et al. / BAWAL. 8 (2) Agustus 2016: 101-108

Williamson, G.R. (1970). Little tuna Euthynnus affinis in http://oceancolor.gsfc.nasa.gov./ Diakses Tanggal 21-3the Hong Kong area. Bull.Jap.Soc.Sci.Fish. (36):9-18. 2013.

Yustina. (2002). Aspek reproduksi ikan kapiek (Puntius schwanefeldi, Bleeker) di Sungai Rangau - Riau, Sumatera. Jurnal Matematika dan Sains 7 (1): 5-14. 